\title{
Illuminating math with optics
}

\section{Judith Donnelly, Matthew Donnelly}

Judith F. Donnelly, Matthew J. Donnelly, "Illuminating math with optics," Proc. SPIE 9188, Optics Education and Outreach III, 918808 (15 September 2014); doi: $10.1117 / 12.2058498$

EDIE Event: SPIE Optical Engineering + Applications, 2014, San Diego, California, United States 


\author{
Illuminating math with optics \\ Judith F. Donnelly*a, Matthew J. Donnelly ${ }^{\mathrm{b}}$, \\ ${ }^{a}$ Three Rivers Community College, 574 New London Tpk., Norwich, CT USA 06360 \\ ${ }^{\mathrm{b}}$ St. Bernard School, 1593 Norwich-New London Turnpike, Montville, CT USA 06382
}

\begin{abstract}
Forty-five high school students engaged in hands-on optics applications of pre-calculus topics. Pre- and post-testing was conducted to determine changes in attitudes towards mathematics education. Experiments were performed in community college labs and in the high school classroom, facilitated by college and high school faculty and with the assistance of SPIE student chapter members. We will describe the structure and activities of the four-month program and pre/post test results.
\end{abstract}

Keywords: Education, active learning, secondary mathematics, outreach

\title{
1. INTRODUCTION
}

Pre-calculus is often a very difficult subject for students to learn, even more so than calculus. The number of greatly varying topics gives the sense that the course has a lack of continuity, and many of the applications of pre-calculus topics are not immediately obvious. Poor understanding of pre-calculus topics causes many students to struggle with calculus and more advanced mathematics courses.

The idea for Illuminating Math with Optics originated in 2012, when a group of St. Bernard School (SBS) students was recruited to assist in the development of a video showing how problem-based learning (PBL) engages students in a classroom. To make the video more realistic, the chosen students had not used the PBL method in any of their coursework. An experienced PBL practitioner led them in a day-long exercise to solve a real-world problem involving laser safety. The activity was video-recorded and edited and is part of the PBL Projects YouTube channel. ${ }^{1}$ Students' reactions to the teaching method were extremely positive with some commenting that the exercise showed what math is "for". According to one student, "In math I'm always like 'How does this relate to a real world problem?' And this actually showed how math relates to something that could happen in the real world." The students requested more such experiences and that inspired the authors to apply for an outreach grant from SPIE to integrate optics applications into pre-calculus courses at SBS. The proposal was funded for the 2013-2014 academic year.

Three of M. Donnelly's pre-calculus classes (total 45 students) took part in the program. Pre-post testing was conducted to investigate changes in student attitudes toward mathematics over the course of the year-long program. Working from the pre-calculus syllabus, we chose topics with interesting optics applications, including logarithms, exponential functions, trigonometry, matrices and conic sections. A pre-test (described below) was administered before the enrichment activities began. The students were mostly high school juniors along with a few sophomores and seniors. The students had taken "physics first" as freshmen, a course covering the basic principles of physics. None had taken an optics course, although some students recalled learning some facts about light in physics or chemistry.

\section{FALL KICK-OFF EVENT: TRANSCENDENTAL ENLIGHTENMENT}

In October 2013, thirty-two of the high school students spent a full day participating in workshops at Three Rivers Community College (TRCC). Some students chose to remain at the high school rather than attend because of assignments or tests they felt could not be missed. The goal of the day was to engage students in activities in optics/photonics that revealed the "use" of math principles, in particular, logarithms and exponents. Since these are among the so-called transcendental functions the theme of the day was Transcendental Enlightenment, Illuminating Math with Optics. (See Figure 1.)

*jdonnelly@lasertechonline.org

Optics Education and Outreach III, edited by G. Groot Gregory, Proc. of SPIE Vol. 9188,

918808 (c) 2014 SPIE · CCC code: 0277-786X/14/\$18 · doi: 10.1117/12.2058498 
Students were greeted with snacks and an introduction to the day's agenda (and the reasons for choosing the particular activities), and each student received a tee shirt and a personalized laser engraved dog tag bearing the day's logo. The anodized aluminum dog tags were fabricated by TRCC students, using the college's laser engraver. Students were divided into three groups that rotated among the one-hour workshops. Facilitators were the authors, TRCC faculty, and members of the Three Rivers SPIE Student Chapter. A pizza lunch was also provided and there was ample time allowed for high school students to interact with college facilitators

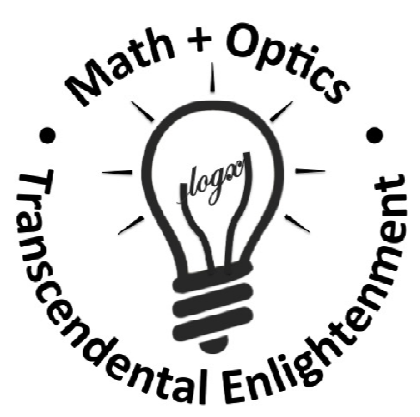

Figure 1. Logo for the day of workshops on optics applications of logarithms and exponential functions

\subsection{Application of logarithms: Fiber optic attenuation}

Students in this workshop were first asked how they would solve a fiber optic power budget problem given input power in $\mathrm{mW}$ and loss for each component in percent. After this short but tedious exercise, they were reminded of the additive property of logarithms and then introduced to the concepts of using $\mathrm{dB}_{\mathrm{m}}$ to measure power and $\mathrm{dB}$ to measure gain and loss. The power budget problem was then quickly solved without the aid of a calculator.

With an understanding of the ability of logarithms to simplify loss calculations, groups of 3-4 students were given $15 \mathrm{~m}$ of plastic optical fiber with a connector on one end and the other end polished (cut with a hot-melt knife) but not connectorized. They were provided with a source and meter test set and sent out into the hallway to measure fiber attenuation using the cutback method. After measuring the length of the fiber, they cleaned the connector end with an alcohol wipe, connected it to the source (set at $665 \mathrm{~nm}$ ) and stretched the fiber the length of the hall to the meter. Three Rivers students helped each group arrange the meter end of the fiber so that it was close to the detector but not touching and the detector shielded from hallway lighting. After the initial power measurement, students used a hot-melt knife to cut the fiber to a length of one meter and once again measured received power. With the aid of logarithms (dB), fiber attenuation was easily calculated in $\mathrm{dB} / \mathrm{m}$. As a reminder of the activity, each student received a short piece of plastic optical fiber to take home to show family and friends. The TRCC outreach group has learned that such souvenirs help get the word out to a larger audience about our programs and activities.

\subsection{Application of exponents: Absorption coefficient of neutral density filters}

In this workshop, students were asked to find the absorption coefficient of neutral density filters of differing optical densities. This was also an opportunity for the high school students to work at "professional" optical workstations in a darkened optics laboratory. Students were given a low power HeNe laser, an optical power meter and a set of five identical gelatin ND filters mounted in slide holders. The students measured the power transmitted though combinations of one through five filters. After calculating the transmittance for each filter configuration, they were asked to plot a graph of transmittance versus total filter thickness. Using Vernier Graphical Analysis software, they performed a best-fit curve to the data and determined the value of the absorption coefficient in $T=e^{-k x}$.

Students were then asked a number of questions based on their results, for example, do darker filters have a higher or lower value of $k$ than lighter filters? Finally, the facilitator pointed out that the filters were stamped with an optical density value, not absorption coefficient, and the conversion from base $e$ to base 10 was reviewed.

\subsection{Math potpourri: Manufacturing and laser engraving}

In this workshop students designed, engraved, and cut wooden personalized wooden key tags using an Epilog 45 watt laser engraver. SPIE student chapter members also gave a "tour" of the laser, showing where the laser is housed and 
pointing out the mirrors of the beam delivery system. Students were told that the engraver's $\mathrm{CO}_{2}$ laser was manufactured in Bloomfield, CT at Coherent, Inc., a short trip from campus. Coherent is one of the employers of TRCC Laser and Fiber Optic Technology program graduates. Also in the manufacturing lab, the high school students were introduced to the concepts of laser scanning and 3-D printing, and watched as small yellow plastic ducks slowly took form in a 3D printer. A Three Rivers faculty member demonstrated CNC machining and programming a robot arm in a model manufacturing cell and pointed out the many applications of mathematics needed in advanced manufacturing.

\section{CLASSROOM VISITS}

After the initial workshops at Three Rivers, the activities moved to M. Donnelly's mathematics classroom at SBS. There were four visits, in December 2013 and January and March 2014 with the post-survey administered in late March. The fourth visit in May was "just for fun", a reward for working hard during the school year. The biggest challenge of the classroom visits was packaging background materials, hands-on experiments and conclusions into the short 42-minute class periods. This required some of the theory and/or conclusions be assigned as homework or covered in class before or after the visit. Three classes took part at each visit, with class size ranging from 5 to 25 .

\subsection{What can you do with trigonometry? Measure the wavelength of light}

After an introduction to wave interference with examples from acoustics, students were shown how to use a diffraction grating to measure the wavelength of light from a red laser pointer. (See Figure 2.) Students applied their knowledge of trigonometry to determine the diffraction angle for several fringes, and then used the two-slit equation to calculate the wavelength. They were also asked to make predictions about what would happen with a longer or shorter wavelength and different slit spacing. Additional gratings and laser pointers were available to test their predictions. This activity took longer than the allowed class period and every class required a second day of class time to finish their work. The written activity report was graded and used as part of the math course grade.

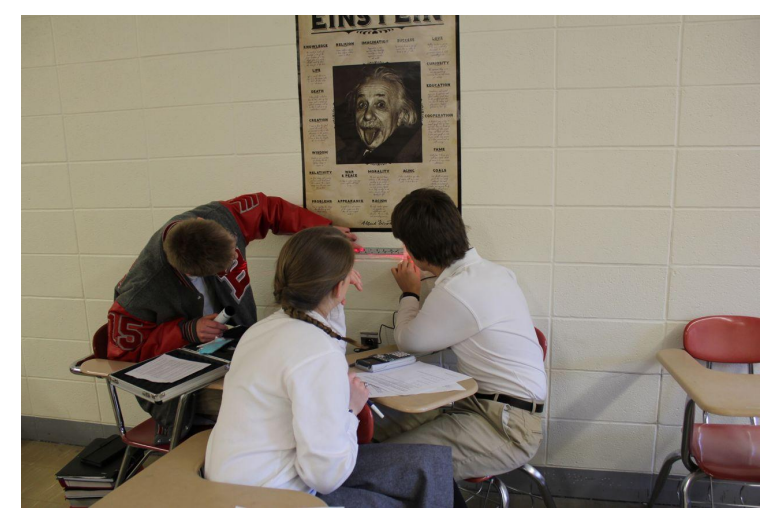

Figure 2. Students measure diffraction fringe spacing under the watchful eye of Albert Einstein in the math classroom.

\subsection{What's a matrix for? Modeling a simple lens}

This was the most challenging activity because of the amount of prerequisite knowledge required for results to make sense. Nonetheless, the authors felt it was an essential exercise because their own recollections were that matrices, more so than other topics they studied in high school mathematics, seemed to have no useful applications.

Students were given two preliminary optics homework assignments: the first was a vocabulary worksheet for the essential concepts of rays, index of refraction, Snell's law, lens shapes, focal length and the small angle approximation. The second assignment, Magic, Refraction and Trig, asked students to perform the "appearing penny" illusion by placing a penny in a small cup placed on a table so that the penny cannot be seen and adding water until the penny becomes visible. The "magic" was explained using ray diagrams and students were then asked to calculate the angle of refraction using Snell's law. 
On the day of the classroom visit, students were shown a simple double convex lens and, with their knowledge of refraction, geometry and trigonometry, discussed how they might trace the path of a ray of light through such a lens. They were then presented with a diagram of the seven-lens system in the camera of one of the authors and agreed that ray tracing through this system would be very tedious indeed. We then described how complex lens systems could be viewed as a series of refractions and translations and introduced the matrices describing each of these. As proof of concept, students were given a flat acrylic semi-circular "lens" and asked to write the three applicable matrices (refraction, translation, refraction) and to compute the system matrix. From the system matrix elements they calculated the (back vertex) focal length and then measured the focal length using a laser ray box. (See Figure 3.) Measurements compared amazingly well to predictions, at least well enough to convince students that matrices could indeed prove useful in the "real world". Again, the report for this exercise was graded and used as part of the math course grade.

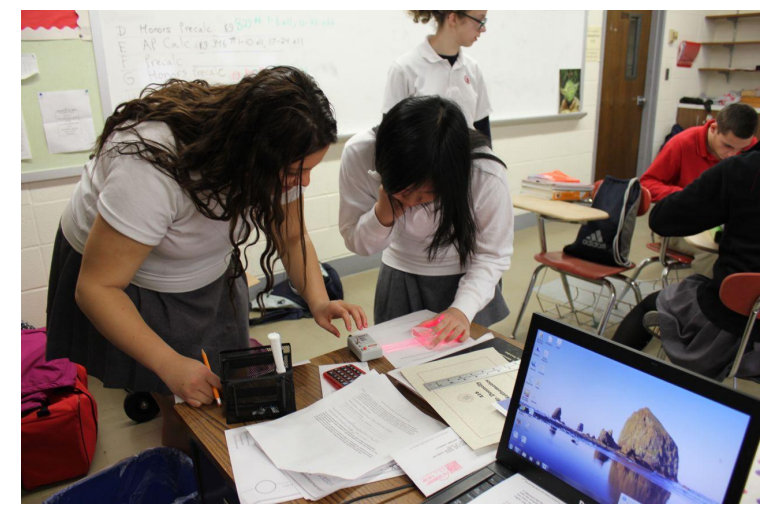

Figure 3. Students use a ray box to measure the focal length of an acrylic lens shape.

\subsection{Conic sections: Telescopes and edible math}

The short presentation for this exercise introduced the law of reflection and the concept of mirror geometry based on conic sections. Examples presented ranged from everyday parabolic reflectors in flashlights and headlamps to ellipsoidal laser cavities and the complex mirrors of the Hubble, Spitzer and Chandra telescopes along with representative photos taken by each. While we would have enjoyed building a telescope, neither budget nor time would allow such a project. Instead, students created (and ate) their own conic sections from cone-shaped cakes and chocolate frosting or fruit spread. (See Figure 4.) The cone-shaped cakes were made following the directions for Sconic Sections ${ }^{2}$ but using packaged cake mix rather than scones. Cake cones proved to be easier to make and to cut with plastic knives.
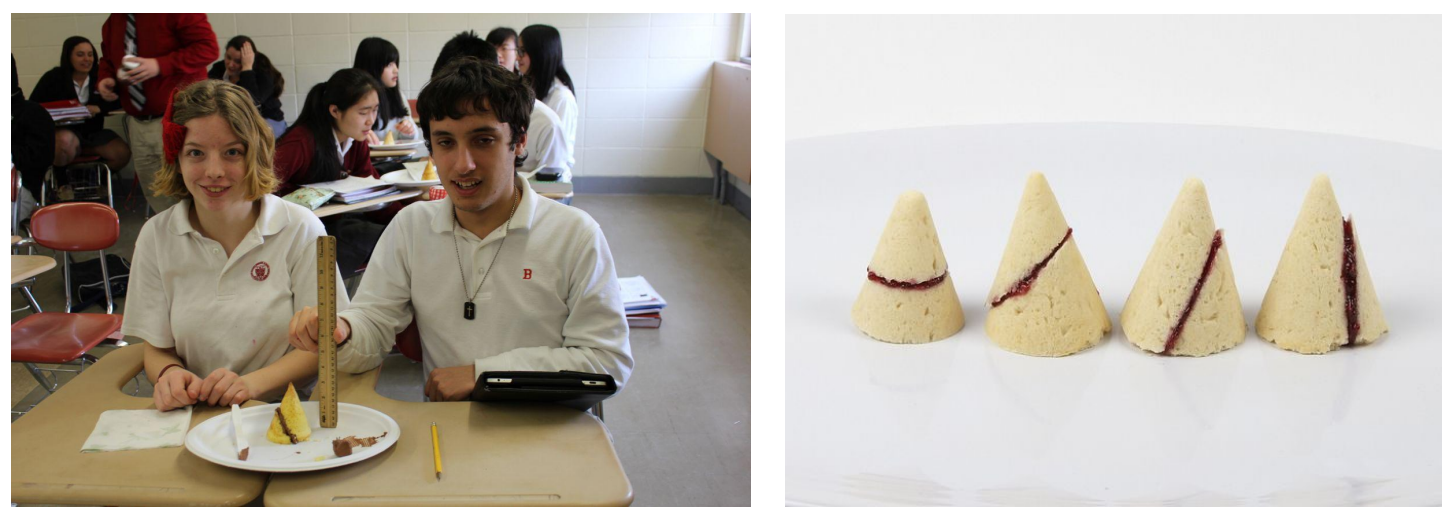

Figure 4. Students display their edible parabola (left). The author's edible conic sections. (right) 


\subsection{Twisting light: Polarized light art}

This hands-on activity was end-of-year bonus, completed after the post-survey as a fun "thank you" to students for their participation in the optics hands-on activities. The AP calculus class was included as well as the three pre-calculus classes. Students worked through a brief lab experiment on polarization concepts from the online version of TRCC's Introduction to Light and Lasers course. This inquiry-based activity uses a series of questions and investigations to introduce students to polarization and birefringence. Students also examined stress patterns in a U-shaped plastic piece and in their own eyeglasses using large $(10 \mathrm{~cm})$ framed pieces of polarizing film. The frames were laser cut and assembled from cardboard by TRCC students.

After the polarization lesson, students were given a smaller $(3 \mathrm{~cm}$ diameter) laser cut piece of laminated polarizer film and assorted pieces of laser cut cellophane. Students attached the circular "viewer" polarizer to the square frame with a string. The cellophane pieces were attached to a square of transparency film with cellophane tape and then viewed between the polarizers. (See Figure 5.) The transparency film was used rather than taping directly to the polarizers to protect the film for future experimentation. Students also saw the artistic possibilities of the medium by visiting the website of Austine Wood Comerow, creator of the art of Polage. ${ }^{3}$ Although this lesson intentionally did not emphasize mathematics, the authors were please that students, particularly in the calculus class, asked about the vector nature of the electric field and how it was related to Malus' Law.
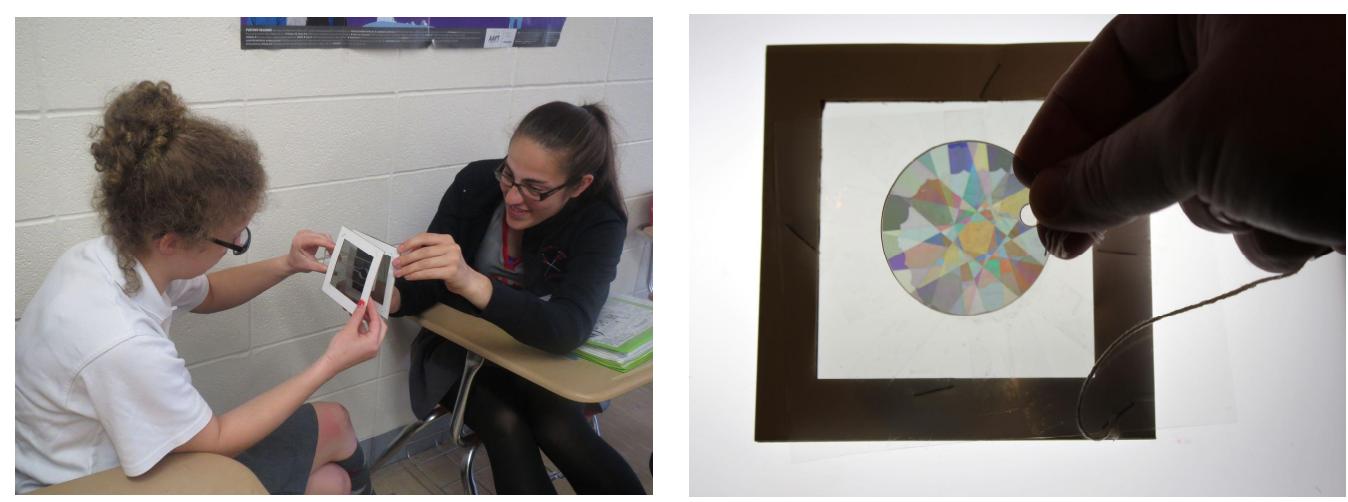

Figure 5. Students examine a stressed plastic "U" shape between crossed polarizers (left); A completed "art" project (right)

\section{PRE/POST SURVEY RESULTS AND STUDENT REACTIONS}

The survey used for pre-post testing was adapted from the Student Engagement in Mathematics (SEM) developed by Kong, Wong and Lam (2003). ${ }^{4}$ The original work was developed to measure cognitive, affective and emotional engagement of middle school students in Shanghai; thus, some of the survey statements were not appropriate to our effort with U. S. high school students. We were most interested in the statements related to pre-post changes in students' strategies for learning mathematics (making connections among math topics and with other school subjects) and in their interest in learning math. Our hypothesis was that connecting math topics to new and interesting topics in optics/photonics would lead to an increase in both areas. All students had been in Donnelly's algebra courses the previous academic year so instructor was not considered a variable in this case.

The pre-survey was presented before the first activity (the TRCC campus visit) and the post-survey after the fourth activity in March, 2014. Because of absences, only 28 students participated in both the pre and post testing; this may have affected results since several of the missing students were in the honors sections and most enthusiastic about the hands-on activities. Although we were looking particularly at the 13 strategies and interest statements, students were asked to respond to all the statements in the SEM using a 5-point Likert scale. Paired t-tests were performed in Excel on the pre and post survey averages for each statement. A summary of our analysis of the results is below.

Of the 13 SEM statements in the strategies and interest sections, two resulted in a significant increase $(p \leq 0.05)$ :

When I learn mathematics, I wonder how much the things I have learned can be applied to real life. (strategies) 
I am very interested to know how to solve new mathematics problems. Mathematics always gives me pleasure. (interest)

The remaining statements from these two sections showed a slight non-significant increase or no change at all (no decrease). Although not of primary interest for this project, we did notice significant increases in other areas of the survey, in particular for the statements:

Learning mathematics is tough, but I am happy as long as I can good results. (motivation)

I find myself very nervous during mathematics tests. (anxiety)

I use every means to understand what the teacher teaches in mathematics. (attentiveness)

Students were also asked to provide written comments on the end-of-year course evaluation form. While not every student did this, those comments that were provided were very positive and supported the results of the pre-post testing, for example:

Thanks for making math relevant. The projects were nice; math is much more fun when we can understand the applications.

Loved the projects, they helped me understand what we were doing in class. A little more time to work on them would be good.

The math labs we did in class with Mrs. Donnelly were very beneficial to my and, I believe, the majority of the class' learning. They gave answers to the timeless question, "When am I going to use this in real life?" as well as making mathematics interesting, fun, and sometimes even tasty. Whether she came to us or we left the school to go see her, Mrs. Donnelly's labs were something we all looked forward to and frequently leave us wanting more out of math than just homework.

The experiments allowed me to eyewitness the mathematics concepts we were learning in class in the real world. Also, I have a better understanding of light and optics than I had before. This information has helped me in other classes and in real life situations. So now instead of just seeing bends in light and the colors of lasers, I know how to read my prescription from my optometrists and how to use lasers safely. I also better understand where these things exist in our world, such as polarized materials, and optic fibers in my own home. This is all thanks to my optics knowledge developed throughout this program.

\section{CONCLUSION AND FUTURE PLANS}

We provided enrichment to three high school pre-calculus courses in the form of hands-on experiments in optics/photonics. Results of a pre/post survey plus student written comments indicated an increase in students' appreciation for the applications of mathematics as well as a better understanding of optics/photonics. For many students, it was their first exposure to optics/photonics.

We noticed in the pre-post test results that many students indicated a feeling of frustration and anxiety on math homework and exams. We plan to address this during the 2014-2015 academic year by including STEM (in particular optics/photonics) applications of mathematics in the form of problem-based learning (PBL) exercises. This instructional method includes the explicit teaching of structured problem solving or, "knowing what to do when you don't know what to do". A pilot study of community college students demonstrated that engaging in problem based learning resulted in gains in motivation, self-efficacy and critical thinking skills. ${ }^{5}$ As experience with PBL increased, students developed the confidence and problem-solving skills needed to analyze and solve ill-structured problems. We hope to replicate these results with high school mathematics students. We also plan to develop a new pre/post survey that will be more appropriate to U.S. high school students and PBL. 


\section{ACKNOWLEDGEMENTS}

This project was funded by an outreach grant from SPIE with support from Three Rivers Community College's SPIE Student Chapter

\section{REFERENCES}

[1] New England Board of Higher Education, "Engaging Students in Problem Based Learning, "NEBHE ProblemBased Learning Channel, https://www.youtube.com/playlist?list=PLP124WShNGz1gEVCA4DuXN_AbG6_ygt46.

[2] Evil Mad Scientist, "Play with your food: How to make sconic sections", http://www.evilmadscientist.com/2013/sconic-sections/

[3] Austine Wood Comerow, "Handmade morphing light art", http://austine.com.

[4] Kong, Q., Wong, N, and Lam, C. "Student Engagement in Mathematics: Development of an Instrument and Validation of Construct", Mathematics Education Research Journal, Vol 15, No 1, pg 4-21, 2003.

[5] Massa, N. M., Donnelly, J. F., and Hanes, F. D. "Student Reactions to Problem Based Learning in Photonics Technician Education", Proceedings of the Education in Optics and Photonics (ETOP) Conference, Porto, Portugal, 2013. 